\title{
Uma observação sobre o épico em Um dia ouvi a Lua, de Luís Alberto de Abreu
}

A view about the epic in

Um dia ouvi a Lua, by Luís Alberto de Abreu

Luís Roberto Arthur de FARIA ${ }^{1}$

\section{RESUMO}

Este artigo discute como o autor Luís Alberto de Abreu define a linguagem épica em textos teatrais. Como exemplo de análise, a peça Um Dia Ouvi a Lua.

Palavras-chave: Linguagem épica. Narrativa. Teatro.

\section{ABSTRACT}

This paper discusses how the author Luis Alberto de Abreu defines the epic in drama. As an example for analysis, an extract of the play Um Dia Ouvi a Lua.

Keywords: Epic language. Narrative. Theater.

\author{
1. Doutorando em Artes da Cena \\ pela Unicamp. \\ ORCID: http://orcid.org/ \\ 0000-0001-9217-7652 \\ E-mail: lafarialuis11@gmail.com
}

Submetido em: 21/07/2015, aceito em: 04/01/2016. 
Luís Alberto de Abreu, em seu texto teórico A restauração da narrativa, publicado no livro Luis Alberto de Abreu: um teatro de pesquisa (2011), busca discutir a questão da restauração da atitude narradora, configuradora da linguagem épica, especialmente no Brasil, partindo curiosamente da notação de um aspecto: a arquitetura. Esta faz Abreu sugerir que a noção de imaginário comum está em franca decadência atualmente, o que afeta a capacidade de produção narrativa, o que, por sua vez, pode ser atestado na arquitetura das cidades brasileiras. Nas cidades coloniais brasileiras, diz ele, as moradias eram construídas de acordo com o padrão de portas e janelas abertas (cerradas apenas à noite) à rua e à praça, e vice-versa, sendo essa forma um constructo simbólico de acesso fácil e livre de embaraços ao espaço íntimo e privado da casa. O mundo privado e o mundo público possuíam estreita relação.

A noção de corpo social e o compartilhamento de experiências particulares contribuíam, dessa forma, para a construção de um imaginário coletivo. Toda experiência humana terá valor simbólico caso haja troca entre os sujeitos, criando-se um repertório comum de uma consciência coletiva. Ao perder contato com a rua, a praça e com a comunidade, o homem reduz a quantidade e a qualidade de seu repertório a ser comunicado. Seu repertório de imagens reduz-se àquelas geradas apenas a partir de si próprio (de seus sentimentos) e advindas do contato com seu reduzido círculo familiar e meio social (moral). Essa perda de contato pode ser evidenciada na arquitetura mais contemporânea: entre a soleira da casa e a rua, há quintais, calçadas, muros, portões, grades, lanças, cacos de vidro, interfones. A relação para com esta forma está além das questões de segurança, está na relação das pessoas com a questão de se estabelecerem barreiras sociais demarcadas pelo status individualista. Assim, abandonando a rua, o homem abandona sua capacidade de aprender, distanciando o (pouco) que sabe do sentir. Seus sentimentos tornam-se mais rasos, posto que longe do conflito com a complexidade do mundo real. A perda de contato social liga-se à decadência do imaginário coletivo, o que, por sua vez, leva à decadência da narrativa.

Abreu, claro, não torna a discussão unilateral. Sugere que, por outro lado, a perda da noção de corpo social não é negativa: permitiu ao homem pensar o mundo a partir de seu fortalecimento enquanto indivíduo, fortalecendo-lhe a independência e sentindo, em contrapartida, o peso da responsabilidade dessa situação. Deu dois exemplos que definiu como protótipos do homem moderno: o Davi de Michelangelo, de semblante pensativo e aflito, carregando o peso da existência; e o Hamlet de Shakespeare, que oscila, conflituosamente, entre honrar o passado medieval representado pela família e seguir 
os seus próprios desejos. Ambos os exemplos representam o homem carregando o peso de seu conflito perante a natureza e o corpo social.

Mas, como sugerido, o gradativo isolamento do indivíduo, dado por contextos históricos, tais como as revoluções burguesas dos séculos XVIII e XIX, que geraram uma nova ordem urbana, definiu indivíduos descolados do senso de comunidade. As artes cênicas sentiram isso. Essa é a razão da predileção pelo melodrama já no século XIX, no teatro, e, além, nos séculos $\mathrm{XX}$ e XXI, no cinema e na TV, o que trouxe aspectos positivos e negativos.

Em outro texto, A personagem contemporânea: uma hipótese (Ibidem, 2011), Abreu discute como a personagem melodramática pode apresentar importância para o teatro. Usa como exemplos Blanche Dubois, de Um bonde chamado desejo e James Tyrone, de Longa jornada noite adentro. Essas personagens são complexas -e, portanto, grandes criações-, porque estão perplexas diante de fatos que não compreendem. São personagens que reconhecem seus problemas, mas não a raiz do mal que as atinge; reconhecem-se, de certa forma, fracas, buscando refúgio nas famílias e nos seus frágeis sentimentos diante de um mundo cruel, caindo facilmente em desgraça ${ }^{2}$. Longe do melodrama, são personagens de mesma cepa as kafkianas; ou aquelas que nem memória possuem, promovendo discursos passivamente ansiosos, como as de Esperando Godot; ou, ainda, as de textos pós-modernos, que são ansiosas e ativas, destrutivas ou autodestrutivas.

No entanto, há personagens melodramáticas que passam pelo problema do artificialismo maniqueísta. Podemos ver essa situação em personagens pouco complexas em diversas produções cinematográficas também de menor complexidade e em diversas telenovelas nacionais e estrangeiras, produções que, em sua maioria, levam o público mais a atingir o território subjetivo das sensações individualistas. Além dessa problemática, há a questão do privilégio da quarta parede como uma instituição, o que, por vezes, dificulta a aceitação de diferentes formatos dramáticos. A TV e o cinema, aliás, acabam sofrendo do próprio mal: obras mais complexas, diferenciadas, acabam tendo pouca aceitação, pelo condicionamento do espectador.

Assim, podemos colocar que Abreu sugere, em resumo, que a reconfiguração da arte teatral deve surgir a partir de uma leitura do real, observando-se suas forças. Acredita ele que a linguagem épica seja uma grande forma de reorganização do teatro ${ }^{3}$, posto que apoiada na narrativa. A linguagem épica, para ele, organiza imagens, tal como a narrativa épica tradicional. A narrativa épica tradicional, diz Abreu (Ibidem, 2011), é construída, segundo Aristóteles, de modo a permitir que
2. Abreu coloca que as personagens trágicas clássicas, como sabemos, se reconhecerem seu erro a tempo, podem tentar repará-lo. O erro trágico, aliás, afeta toda uma comunidade. Com o drama burguês, a personagem tenta moldar o mundo a partir de seus valores individuais ou de seu grupo familiar. Nos dois gêneros, as personagens lutam, tentam agir em relação à realidade; sua queda relaciona-se à percepção dessa necessidade de agir.

3. Acredito também que Abreu pense no cinema e na $\mathrm{TV}$, posto já ter escrito para essas mídias. 
várias coisas sejam narradas a partir de um mesmo leitmotiv. Nesse sentido, pois, por meio da narrativa, o espectador pode criar imaginativamente o espetáculo, deixando a sua imaginação correr. É o que acontece, a meu ver, na peça recentemente encenada por Juca de Oliveira, o Rei Lear shakespeariano, na qual o ator encarna o próprio rei, em um monólogo em que narra os acontecimentos da trama, o que é feito sem a ajuda de cenários suntuosos; há apenas o próprio ator, vestindo uma roupa preta, neutra; no palco, uma cadeira 4 .

Abreu insere-se no Brasil no momento em que a desconstrução da cena era a tônica. Após a abertura política do país a partir da Anistia, os escritores de peças teatrais viram-se de certa forma "perdidos", já que o motivo de suas peças, o combate ao inimigo ditador militar e suas forças de adensamento, estava, de certa forma, fora de questão. Os paradigmas estavam se modificando. Um novo estatuto de produção dramatúrgica manifestava-se: a produção textual a partir do contato com a esfera da encenação. Se, antes, era mais comum o texto ser pensado primeiro e a encenação acontecer em seguida, a partir dos anos 80, tornou-se comum o trabalho conjunto de construção cênica e produção textual, o que abriu espaço para uma multiplicidade de formas textuais e de encenações. Abreu insere-se nesse momento, escrevendo textos das mais variadas temáticas. Por escrever sobre temas diversos de interesse público, é conhecido por ser um autor com uma pluralidade de estilos e de grande diversidade de linguagens. Trabalhando junto ao encenador, determina o gênero, se mais voltado ao dramático, se mais ao cômico, ambos apoiados no épico, a partir da encenação. É comum ele até mesmo buscar elementos para seus textos no edifício onde a encenação vai se apoiar, exemplar disso sendo O livro de Jó, encenada em um hospital, um espaço não convencional, sobre a qual também farei menção neste artigo.

É interessante, neste momento, apresentar pelo menos um trecho de texto teatral de Abreu que represente essa questão do épico em suas peças. Vou me utilizar de um texto da peça Um Dia Ouvi a Lua (Ibidem, 2011, págs. 568-9). A trama é inspirada em três músicas: "Adeus, Morena, Adeus" (Piraci/ Luiz Alex), "Cabocla Tereza" (João Pacífico/ Raul Torres) e "Rio pequeno" (Tonico/ João Merlini), todas gravadas nas décadas de 1950 e 1960 pela dupla sertaneja Tonico e Tinoco. No entanto, na peça, inverteram-se os valores machistas das narrativas nessas composições, colocando também a mulher como protagonista. Se na música "Adeus, Morena, Adeus", por exemplo, o violeiro segue para o Paraguai deixando a Morena para trás, na peça, a moça ganha nome, Beatriz, e dá ao espectador a sua versão da história. Em "Cabocla Tereza", a moça, embora morta, volta
4 Rei Lear, apresentado em São Paulo no Teatro Eva Herz entre 2014 e 2015 na Livraria Cultura da Avenida Paulista. Monólogo com Juca de Oliveira. Tradução e adaptação de Geraldo Carneiro. Direção de Elias Andreato. 
para esclarecer o seu trágico fim. Tereza foi morta pelo marido supostamente traído. E, em "Rio Pequeno", S’a Maria abandona os pais e segue com o caboclo Cipriano para Mato Grosso. No entanto, no caminho, observa a violência do amado no trato com o seu cavalo e decide voltar. O texto, escrito em 2010, foi interpretado pelos seis atores da Cia. Teatro da Cidade, de São José dos Campos, que viveram diversas personagens, utilizando-se da narrativa para contar as possíveis versões das histórias. Foi utilizada a técnica do teatro Nô, com poucos elementos no cenário e no figurino ${ }^{5}$.

A peça é construída e reconstruída a cada momento, a cada sequência. A relação com o universo feminino e também com o universo infantil permeia todo o espetáculo. Todas as mulheres no espetáculo sofrem algum tipo de agravo na relação com o polo masculino. As crianças também aparecem como figuras que comentam o universo dos adultos e também trazendo um imaginário das ruas e das praças de cidades de tempos atrás. Trago um trecho da sequência "Adeus, Morena, Adeus”, o início, em que essas relações estão visíveis.

\section{ADEUS, MORENA, ADEUS}

Crianças brincam, uma delas se destaca e vai para frente.

CRIANÇA 1 - Olha a Beatriz!

As crianças observam, com algum receio, a mulher que passa; depois retomam a brincadeira.

BEATRIZ VELHA - Todo fim de tarde, Beatriz percorria, calada, a velha estação de ferro desativada. Deitava um olhar triste sobre os trilhos tomados pelo mato, sobre as molduras e colunas de ferro comidas de ferrugem, sobre as paredes de tijolos estragados pelo tempo. Não era louca, acho que só era esquisita. Tinha uns cinquenta anos... pra mais? Talvez. (Transita para a personagem-narradora.) E eu, que agora sou Beatriz, digo a vocês que velhice é cansaço e que hoje, finalmente, meu coração envelheceu. Por tantos anos esperei, não espero mais! (Permanece indecisa um momento, depois senta-se.) Mas se esperei tantos anos que custa esperar mais um dia!

CRIANÇA 1 - E era assim. Entra dia, sai dia, morre o sol, nasce a lua, dia fazendo pilha de mês, mês fazendo rosário de anos e aquela mulher toda tarde passeava pela velha estação. Um dia um homem que ninguém conhecia apontou na rua.

Crianças param de brincar e observam o homem que entra com um violão às costas. Depois correm para todos os lados.
5. Não vou me ater aqui a uma discussão sobre o Nô, pois é ainda é objeto de pesquisa para minha tese. 
CRIANÇA 2 - Foi um zum-zum-zum pela vizinhança... quem é, quem não é o desconhecido? É primo distante, parente de quem?

CRIANÇA 1 - E se for o homem do saco?

CRIANÇA 3 - Homem do saco não carrega viola!

CRIANÇA 2 - Pergunta!

CRIANÇA 4 - Eu não, sua tonta!

VIOLEIRO VELHO - Sou Manoel Benedito, Mané-dito, sobrenomeado, e me pergundo se não foi nesta cidade tão crescida e mudada que um dia passei pra levar, farpado no peito, o maior desgosto que pude carregar pela vida afora. (Subitamente chora.)

CRIANÇA 4 (chocada com o homem) - Credo! (Corre chamando.) Vó!

CRIANÇA 3 - Manoel Benedito... disse minha vó cavocando um resto de memória... Conheci um, violeiro bão, faz tempo que se perdeu pelo mundo pra nunca mais se ver!

VIOLEIRO VELHO - Sou esse.

CRIANÇA 2 - Chorando? Num credito, disse minha tia, aquela mais velha... aquela torta, aquela que anda assim, meio fora de esquadro... Ah!, você sabe! Aí, um juntou um caco de lembrança daqui, outro um pedaço de memória dali, uma lasca ou outra do acontecido e logo a cidade montou por inteiro o vaso de porcelana precioso que é essa história. Foi assim, nunca me deixei esquecer. (...)

Temos aqui um trecho iniciado pelas crianças. Para Luís Alberto de Abreu, as crianças consideram as experiências um tesouro a ser reencontrado. Como ele sugere que, pelo épico, olhamos o mundo como uma criança, a qual o descobre pela primeira vez, a participação delas nessa peça é destacável: apresentam personagens, discutem questões relacionadas ao contato com o mundo (sobre o "homem do saco", por exemplo), narram a história. Como a Beatriz Velha, que também narra uma história. Para Abreu, as crianças e as mulheres sempre foram, na História, seres que sofreram com as intervenções do polo masculino dominante. Dar corpo à voz delas é imprimir um imaginário agregador a um mundo dominado pela objetividade da tecnocracia, pela unilateralidade de pensamento, que só busca o progresso material, a disputa por territórios, a luta pelo poder, a mediatização, e deixa de lado sentimentos e emoções, relações interpessoais profundas, contato com a subjetividade. As crianças brincam, não estão relegadas a escolas desde cedo, aprendendo valores mercadológicos, tais como o individualismo e a competitividade pouco saudável -especialmente quando incentivadas apenas a vencer a questão do vestibular-, que as levarão, consequentemente, a serem hipercompetitivas no futuro, o que, por sua vez, destruirá seus sentimentos gregários; que as farão, enfim, querer consumir bens materiais, viver para 
trabalhar e tomar remédios dos mais variados para sustentar sua psique esvaziada de sentido.

A mulher velha que passa é vista com medo. Na infância, em cidades do interior, todos tivemos medo de alguém mais velho que se aproxima para contar alguma história; a mulher mais velha é encarada como uma feiticeira, uma maluca, qualquer coisa nesse universo. Há um quê de respeito, medo, deboche, todos os sentimentos juntos. É interessante notar o receio, justamente porque ele imprime na personagem a característica amedrontadora que a destaca. Mas o receio passa logo: voltam a brincar, a jogar, o que é próprio das crianças.

Beatriz Velha começa a falar e é aí que notamos o épico em movimento no texto. Beatriz Velha passa a falar de outra Beatriz, de uma mulher de 50 anos, que percorria os trilhos da estação de ferro desativada, deitando "um olhar triste sobre os trilhos tomados pelo mato, sobre as molduras e colunas de ferro comidas de ferrugem, sobre as paredes de tijolos estragados pelo tempo". Aqui, vemos a característica da descrição no texto: ao invés de vermos a estação de ferro, o que no cinema de certa forma poderia ser feito, e na TV também, no teatro sugerido por Abreu, vira texto, descrição, e dentro da fala da personagem, que, narrando, revolvendo a memória, retoma um passado que teria vivido e atualiza-o, trazendo-o de volta, mas por meio do signo estético: matos não "tomam" trilhos, ferrugem não "come" colunas de ferro, o tempo não "estraga" paredes. Trata-se de signo estético porque estamos no reino da metáfora e da sinestesia (esta, uma forma de metáfora), das figuras de linguagem, enfim, dos signos estéticos por excelência. Por meio do procedimento descritivo dentro da fala de Beatriz Velha, temos a questão da criação imaginativa do espetáculo: a atriz deve contar isso no jogo do "olho no olho", estabelecendo uma relação de afetação que, por sua vez, estabelecerá o efeito de sentido. Como disse, a memória é revolvida, mas há criação no meio, sugerindo a estação ser tão abandonada quanto a Beatriz de 50 anos que por ali vai andar, na esperança do retorno do amado, o qual, saberemos logo, será o Violeiro.

Em seguida, ao discurso sobre a Beatriz de 50 anos é sobreposto o discurso da Beatriz Velha, que diz que velhice é cansaço -aqui, um processo metonímico, "velhice é cansaço", sendo substituto de "velhos se cansam"-. O coração, ela diz, envelheceu -imagem metafórica, também-, sugerindo a passagem do tempo. Este, aliás, é um elemento que nos atravessa, sendo destacado pela Criança 1, a qual falará "Entra dia, sai dia, morre o sol, nasce a lua, dia fazendo pilha de mês, mês fazendo rosário de anos e aquela mulher toda tarde passeava pela velha estação", querendo trazer o tempo passando, notado não pelo fluxo do calendário, mas pelos elementos naturais, como o sol 
e a lua. Aqui, o nível de consciência da Criança 1 atesta-nos que esta é, na verdade, narradora nesse momento, num discurso que se sobrepõe ao discurso infantil: é a criança que fala, mas a consciência é histórica, que dá voz à memória, falando do tempo que passava e do passeio da mulher pela estação. É a magia teatral: vemos um ator ou uma atriz dizendo um texto utilizando-se da imagem da criança; a essa imagem é sobreposta a voz de um narrador.

Tal como Shakespeare, em Noite de Reis (2001, $2^{a}$ edição) -texto que abordei em minha dissertação de Mestrado ${ }^{6}-$, coloca um ator se fantasiando de mulher para viver Viola, que, depois, se traveste de homem e fica igual ao irmão Sebastião -ou seja, um ator que vira mulher e vira novamente homem, sobrepondo fantasias ${ }^{7}-$, aqui temos um ator ou atriz colocando a máscara da criança e, por cima dela, novamente, a máscara da consciência adulta. Aliás, a não definição clara do sexo das crianças (apenas uma parece ser definida) que falam é interessante: podem ser meninos todos, meninas todas. As crianças representam, nesse sentido, o universo infância metonimicamente, expandindo as possibilidades de atuação para um grupo, formado só de homens, só de mulheres, ou misto, como o é a Companhia de São José dos Campos.

Na peça O Livro de Jó, também de Abreu, temos um trecho que é semelhante estruturalmente ao trecho ora discutido de Um Dia Ouvi a Lua. A título de exemplificação, vou transcrevê-lo abaixo8 (Ibidem, 2011, pág. 491):

$$
\begin{aligned}
& \text { ATOR-JÓ - E Jó ficou só } \\
& \text { E olhou quieto, ao redor, } \\
& \text { A silenciosa devastação. } \\
& \text { E chorou, de desespero, dizem uns; } \\
& \text { De revolta, dizem outros; } \\
& \text { De desalento, ouvi dizer. }
\end{aligned}
$$

Nesse trecho, vemos o Ator que faz a personagem Jó narrar em $3^{\text {a }}$ pessoa o que havia acontecido a sua personagem, após as desgraças abaterem-se sobre ele e sua família, conforme lançado no texto. Anterior a Um Dia Ouvi a Lua (a peça é de 1993), O Livro de Jó traz marcas interessantes: mascarado de Jó, o Ator narra o que acontecera a este, direcionando a narrativa tanto ao público como a ele mesmo enquanto personagem. Conta, além de tudo, sobre o que os outros disseram a respeito dele. A respeito d'O Livro de Jó, Rubens Brito (1999, pág. 141) diz que o objeto da narrativa da personagem que narra é a imagem de Jó, uma visão de Jó que é concretizada pelo trabalho do ator, que a visualiza e que a mimetiza em seu corpo. Rubens Brito ainda diz que se constrói uma máscara
6. Estudei a peça shakespeariana no sentido de fazer uma transcriação do texto original para uma forma contemporânea. A intenção foi a de, a partir de um clássico, criar uma representação que evidenciasse certas questões contemporâneas, tais como $o$ hipertexto, a mediatização da vida, o caos urbano, a violência generalizada. Escrita em forma de fluxograma, a transcriação sugere uma representação próxima da performance. A referência e o link para a dissertação estão na Bibliografia.

\section{A peça "Noite de Reis" conta} a história de Viola, que, após um naufrágio, chega à Ilíria, um lugar misterioso, comandado pelo duque Orsino, este, apaixonado pela bela jovem Olívia. Viola traveste-se de rapaz, e decide servir ao duque como mensageiro, com o intuito de aproximar-se dele. Os problemas então começam a ocorrer, já que Olívia apaixona-se por Viola travestida, agora com o nome de Cesário. O pior é que, travestida de Cesário, Viola fica parecida com seu irmão Sebastião, o qual, por sua vez, tendo sobrevivido ao naufrágio, aparece na Ilíara, confundindo a todos.

8. O texto está também no livro de que ora faço uso para análise, Luís Alberto de Abreu: um teatro de pesquisa (2011). Abreu retoma o tema bíblico de Jó, trazendo-o para nossos dias de hoje: Jó sofre perdas violentas e é atingido por uma enfermidade que faz paralelo com a AIDS. A peça foi apresentada no hospital Humberto Primo, em São Paulo, sendo um dos intuitos do espaço determinado, acredito, trazer uma carga sugestiva de dor, angústia, sofrimento e proximidade com a morte, além do questionamento do vontade de Deus a respeito da salvação humana. 
nesse momento: a máscara do narrador que "coexiste com o personagem e com o personagem-narrador, ao mesmo tempo que se distingue tanto do personagem quanto do personagem-narrador". Personagem e personagem-narrador, nesse estudo, seriam outras duas máscaras.

Esse processo é verificável na peça Um Dia Ouvi a Lua. Basta observarmos a fala da Beatriz Velha, que recortamos:

BEATRIZ VELHA - Todo fim de tarde, Beatriz percorria, calada, a velha estação de ferro desativada. Deitava um olhar triste sobre os trilhos tomados pelo mato, sobre as molduras e colunas de ferro comidas de ferrugem, sobre as paredes de tijolos estragados pelo tempo. Não era louca, acho que só era esquisita. Tinha uns cinquenta anos... pra mais? Talvez. (Transita para a personagem-narradora.) (...)

Beatriz Velha, assim, inicia como máscara do narrador, que coexiste com a personagem e com a personagem-narradora. Menciona a estação de ferro, os trilhos, o mato, a idade. Abreu, ainda, coloca que ela deve, depois desse texto, transitar para a personagem-narradora, ou seja, para outra máscara, a máscara daquela que é personagem e que narra a própria história. Para Carrico (2004, pág. 9), em peças de Abreu, um único ator é veículo a um só tempo de personagens que narram e sofrem a ação do que narraram, conflitando-se entre si, fazendo, além do mais, várias personagens sem trocar de roupa ou sair de cena, apenas o texto identificando quem fala. Coadunam-se trabalho do autor e do ator para construir essa relação. Tal situação está presente tanto n'O Livro de Jó, quanto no texto de Um Dia Ouvi a Lua. Abreu expande a noção de mascaramento presente em Noite de Reis, de Shakespeare.

Avançando em Um Dia Ouvi a Lua, vemos a alternância de máscaras, ou de vozes, que ora debatemos. Assim, a Criança 1 termina sua fala dizendo que um dia um homem apontou na rua, e ninguém sabia de onde vinha. Ela está narrando, não ficando claro se é personagem-narradora ou se é essa máscara que coexiste entre personagem e personagem-narradora. $\mathrm{Na}$ verdade, não há importância: a ambiguidade pela ausência dessa definição no texto tornou-se figurativa. Por não termos certeza, o caminho está aberto a diversas possibilidades.

Há, ainda, uma descrição de crianças indo para todos os lados, já que um desconhecido apontou pela vizinhança. A Criança 2, então, põe-se a falar, também, com colocações que lembram bem a fala da Criança 1: parece uma criança falando, mas também traz a narratividade, o questionamento de todos da vizinhança, que se perguntam quem era aquele sujeito que por ali tinha apontado. O sexo da Criança 2 é definido pela Criança 4, que a chama de tonta quando esta pede que per- 
gunte ao homem que chegou se ele era o homem do saco. Aqui, a narração dá lugar à conversa entre crianças. A ambiguidade figurativa expande-se. Possibilidades expandem-se.

Quando o Violeiro fala, conta seu nome: "Sou Manoel Benedito, Mané-dito", um homem que saíra daquela cidade com o coração em farpas. Ele nota que a cidade estava mudada e que dela saíra levando grande desgosto. Ele é uma personagem-narradora, contando em primeira pessoa o que lhe acontecera. Aqui, as vozes misturam-se: a Criança chama a avó, enquanto a Criança 3 diz a fala da avó misturando-a com a fala de criança que narra para o público. A sobreposição de vozes, de rememoração e de atualização de memória torna-se intensa neste momento: vemos uma criança falando o texto da avó e narrando, tomando-se de consciência, e, enquanto narra, também cria, já que está atualizando um elemento passado enquanto se volta ao público, que, por sua vez, vê uma atriz ou um ator dizendo esse texto com vozes sobrepostas. Novamente, expansão de possibilidades por meio do jogo de máscaras.

Essa sobreposição será intensificada com a Criança 2: ela inicia sua fala mencionando a tia torta que não acreditava que o Violeiro era o Mané-dito. E então: "Aí, um juntou um caco de lembrança daqui, outro um pedaço de memória dali, uma lasca ou outra do acontecido e logo a cidade montou por inteiro o vaso de porcelana precioso que é essa história. Foi assim, nunca me deixei esquecer". Temos aqui um trabalho de memorização sendo definido como um vaso de porcelana precioso, produzido pela cidade toda. Os cacos de memória são juntados coletivamente, formando um corpo coletivo, social, em que o compartilhamento de experiências particulares formam um todo coletivo. E a fala mais estranha dita pela Criança 2, justamente a que tem o sexo definido: "Foi assim, nunca me deixei esquecer". Ora, quem diz isso? Uma criança? Não pode ser, já que essa criança vive o espaço diegético da narrativa. É um narrador? Possível! Mas narrador-personagem? Mas essa fala pode ser também da própria Beatriz Velha, relembrando, um dia, o retorno do homem que um dia ela amou. Mas é a Criança que fala, para o público. Seria essa criança a própria Beatriz, sendo atualizada, então? Mas essa criança vive o espaço diegético da história. E então? Possibilidades diversas dadas pela figuração. Um texto altamente poético, de diversos lances imaginativos, cabendo ao sujeito-ouvinte o trabalho de recriação imaginativa.

O crítico Igor de Almeida Silva (2011), a título de finalização, corrobora aquilo que digo:

(...) os narradores de Um dia ouvi a lua abordam a memória e a experiência para através delas fazerem emergir as esperanças não realizadas do passado, inscrevendo no presente seu apelo por um 
futuro diferente. No entanto, nesta peça o passado também é tratado enquanto reelaboração do presente. Ou seja, ele é ao mesmo tempo memória e invenção. As crianças, que consideram a experiência o grande tesouro a ser reencontrado, imprimem esse caráter ambivalente à montagem. As estórias-canções são contadas como fatos acontecidos de uma pequena cidade do interior, mas também como brincadeiras infantis. Longe de banalizar o tema, os jogos infantis tornam o passado uma recriação do presente, tendo em vista sua própria transformação. Em outras palavras: ao contar o ocorrido, o presente transforma a si mesmo. (...) Cria-se! Por isso, em Um dia ouvi a lua, o passado atende aos apelos do presente em forma de estórias-canções de amor, retratos de uma juventude, aqui, à moda caipira.

A citação acima sugere elementos de interesse de Luís Alberto de Abreu. A questão da memória é um elemento bastante presente, já que, para Abreu, o épico é fundado pela narrativa. É a partir da presentificação de elementos guardados na memória que se funda a narrativa. A memória, entretanto, é ativada no sentido de se reelaborar o presente. É memória criativa, ou, como sugere Leonardelli (2008, pág. 8) em sua tese, atualização do vivido no presente, pelas condições do presente, tornando-se "história pessoal recriada e delineada por especificidades técnicas de cada processo de criação". Abreu escreve e cria as histórias das personagens. Para narrar, traz seu conhecimento de mundo: em Um Dia Ouvi a Lua, buscou em músicas do universo caipira sua temática. Brito (Ibidem, 1999, págs. 129-150), ao estudar a obra de Abreu, faz uma analogia de sua produção com o xadrez -daí a tese desse pesquisador chamar-se Dos Peões ao Rei: tal como esse jogo possibilita infinitas possibilidades de lances, na produção de suas peças, Abreu selecionaria, entre tantos recursos dramáticos, aqueles que trariam lances narrativos mais eficazes. Aqui temos o cerne do épico que ora estudo: cada trabalho possui suas especificidades, as quais determinarão como se atualizará a memória para o trabalho criativo. Colam-se os cacos (o passado), trazendo uma nova forma (o presente), em meio a infinitas possibilidades figurativas. Em Um Dia Ouvi a Lua, essa atitude é evidente. 
ABREU, Luís Alberto de. Luís Alberto de Abreu: um teatro de pesquisa. Organização de Adélia Nicolete. Coleção Textos, 25, SP, Editora Perspectiva, 2011.

BRITO, Rubens José de Souza. Dos Peões ao Rei: o teatro épico-dramático de Luís Alberto de Abreu. Tese apresentada ao Departamento de Artes Cênicas da Escola de Comunicações e Artes da Universidade de São Paulo, como exigência parcial para obtenção do Título de Doutor em Artes. ECA-USP, São Paulo, 1999.

CARRICO, André. Por conta do Abreu: comédia popular na obra de Luís Alberto de Abreu. Dissertação apresentada ao Curso de Mestrado em Artes do Instituto de Artes da UNICAMP como requisito parcial para a obtenção do grau de Mestre em Artes sob a orientação do Prof. Dr. Rubens José Souza Brito. UNICAMP, Campinas, 2004.

FARIA, Luís Roberto Arthur de. Caderno de Dramaturgia: Uma proposta de trabalho a partir de "Noite de Reis", de William Shakespeare. Dissertação de Mestrado, Unicamp, Instituto de Artes. Campinas, SP,2012. Link: http://www.bibliotecadigital. unicamp.br/document/?code $=000878307 \&$ opt $=1$

LEONARDELLI, Patrícia. A memória como recriação do vivido: um estudo da história do conceito de memória aplicado às artes performativas na perspectiva do depoimento pessoal. Tese de Doutorado, curso de Pós-Graduação em Artes Cênicas, USP, SP, 2008.

SHAKESPEARE, William. Twelfth Night, or, What you will. Penguin Popular Classics, 1994. Reprinted 2001.

SILVA, Igor de Almeida. Retrato do amor quando jovem à moda caipira. Fonte: http://www.questaodecritica.com.br/2011/10/ retrato-do-amor-quando-jovem-a-moda-caipira/. Acessado em 21/07/2015. 